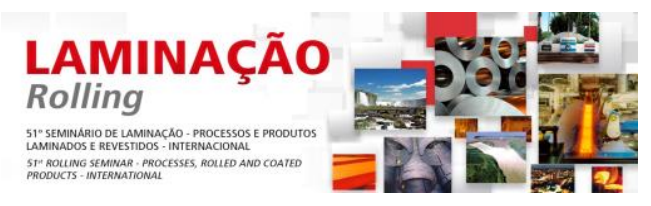

\title{
ESTADO DA ARTE DE BOBINAS PRODUZIDA EM LAMINADOR DE TIRAS A QUENTE: MODELAMENTO E PROCESSO HTP*
}

\author{
Altair Lucio de Souza ${ }^{1}$ \\ Emanuelle Garcia Reis ${ }^{2}$ \\ José Herbert Dolabela da Silveira ${ }^{3}$ \\ Kenji Camey ${ }^{4}$
}

\section{Resumo}

Este trabalho tem o objetivo de apresentar os principais modelos matemáticos e pacotes tecnológicos da nova linha de Laminação de Tiras a Quente da Gerdau e vantagem desses modelos no desenvolvimento de aços HTP (High Temperature Processing). Essa linha tem uma das mais modernas tecnologias de sistemas de automação com modelos matemáticos de alta performance para um laminador a quente.

Palavras-chaves: Modelo matemático; Processo HTP; Laminação a quente.

\section{STATE OF THE ART OF A COIL PRODUCED BY A HOT STRIP MILL: MODELLING AND HTP PROCESS}

\begin{abstract}
This paper intends to present the main mathematical models and packages of the Gerdau new Hot Strip Mill and the advantage of this model in developing HTP (High Temperature Processing) steels. This line is one of the most modern technologies of automation systems with mathematical models of high performance for a hot strip mill.
\end{abstract}

Keywords: Mathematical model; HTP Process and hot rolling.

1 Engenheiro Metalurgista, M.Sc., CQE/ASQ, Assessor Técnico das Laminações da Gerdau Ouro Branco, MG, Brasil.

2 Engenheira Civil, Mestre em Engenharia Metalúrgica e de Minas pela UFMG, Assessor Técnico da Laminação de Planos da Gerdau Ouro Branco, MG, Brasil.

3 Engenheiro Metalurgista, M.Sc., Membro da A.B.M. Gerente da Laminação de Chapas Grossas da Gerdau Ouro Branco, MG, Brasil.

4 Engenheiro Metalurgista, D.Sc., Membro da A.B.M. Consultor Técnico da Laminação de Planos da Gerdau Ouro Branco, MG, Brasil. 


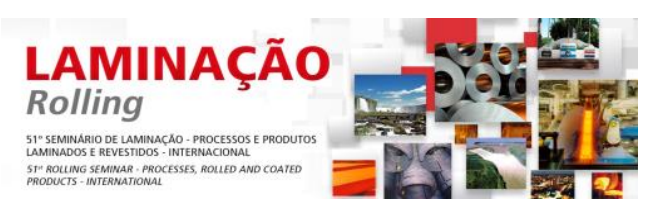

\section{INTRODUÇÃO}

A Laminação de Planos da Gerdau é um projeto de ultima geração em tecnologia de processo, equipamento, automação e operação, consistindo de uma linha de laminação de bobinas a quente com um laminador de tiras a quente e uma linha de laminação de chapas grossas. Os aços laminados atendem aplicações navais, tubos de grande diâmetro, marítima, vasos de pressão, construção civil, máquinas pesadas, agrícolas e estruturais de uma forma geral. As espessuras das bobinas são de 2,0 a $20,0 \mathrm{~mm}$ e larguras de 900 a $2.100 \mathrm{~mm}$; as chapas grossas têm espessuras de 6,0 a 150,0 mm e larguras de 900 a $3.600 \mathrm{~mm}$. A Figura 1 mostra um desenho esquemático das linhas de laminação de planos.

As laminações possuem as mais recentes tecnologias para controle de temperatura, dimensão, forma e qualidade superficial dos produtos laminados, tais como: cálculo do esquema de passes com múltiplos setups ao longo do comprimento da tira, esquema de passes com otimização durante a laminação, controle dinâmico de perfil, controle de forma, smart crown, controle de deslocamento de cilindros (shifting), flexão dos cilindros (bending), controle de resfriamento diferenciado ao longo do comprimento da mesa dos cilindros de trabalho, modelo de controle de forma e perfil do material (plan view), modelo de previsão de propriedades mecânicas, modelo matemático de controle de resfriamento no sistema laminar e no resfriamento acelerado.

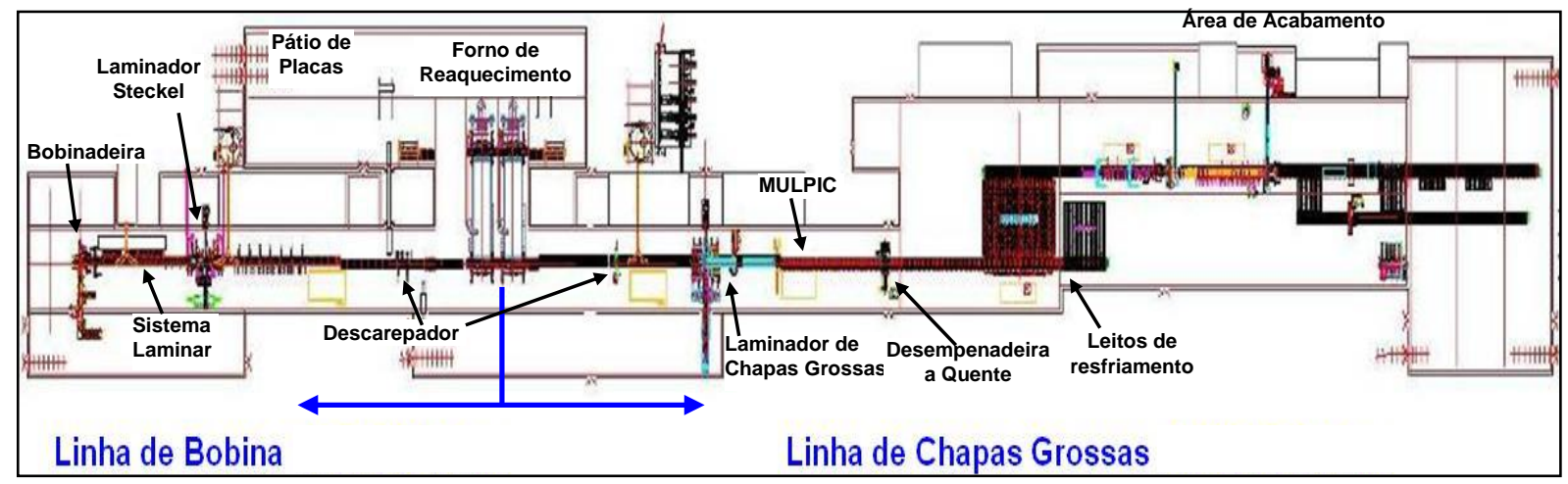

Figura 1: Desenho esquemático da Linha de Laminação de Planos.

$\mathrm{Na}$ linha de bobinas, o controle de qualidade de superfície é realizado por meio do sistema de inspeção on-line para face superior e inferior, no final da mesa de resfriamento laminar, garantindo a inspeção de 100\% das tiras laminadas.

Os controles de dimensões, formas e temperaturas são realizados por meio de sistemas de medição on-line de temperatura, perfil, espessura e largura, garantindo assim um controle on-line das dimensões e das propriedades mecânicas da tira, conforme especificação do projeto do produto laminado.

Essas funções e controles tecnológicos de última geração implantados nas linhas de laminações a quente da Gerdau permitem ter o controle absoluto das variáveis e parâmetros de processo e operação. Com isso, é possível dominar o processo HTP [1-3]. Este processo é uma alternativa viável e interessante para a produção de aços de alta resistência (HSLA), quando comparado com processos atuais mais comuns para a produção desses aços (TMCP, laminação controlada, resfriamento acelerado, tratamento térmico). A Figura 2 mostra esquematicamente a diferença básica entre os processos de TMCP e HTP [3].

O conceito dos aços HTP já existe a pelo menos duas décadas e sua utilização é definida em comum acordo com o usuário final, dependendo da condição de sua

* Contribuição técnica ao $51^{\circ}$ Seminário de Laminação - Processos e Produtos Laminados e Revestidos, 28 a 31 de outubro de 2014, Foz do Iguaçu, PR, Brasil. 


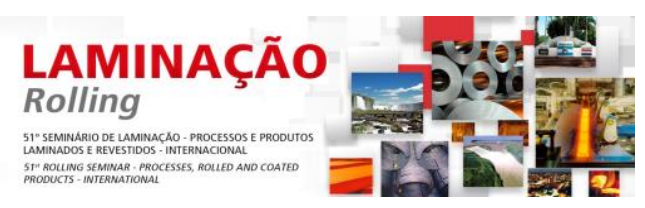

aplicação. Estima-se que a produção total desses aços HTP atualmente seja da ordem de 2.000.000t. A produção de aços HTP em forma de bobina a quente conduz a uma grande vantagem econômica para os fabricantes de tubos de grande diâmetro, pois pode-se produzir muitos tubos com uma única bobina pelo processo helicoidal. Esse processo é uma alternativa interessante em relação ao processo UOE que utiliza chapas grossas discretas.

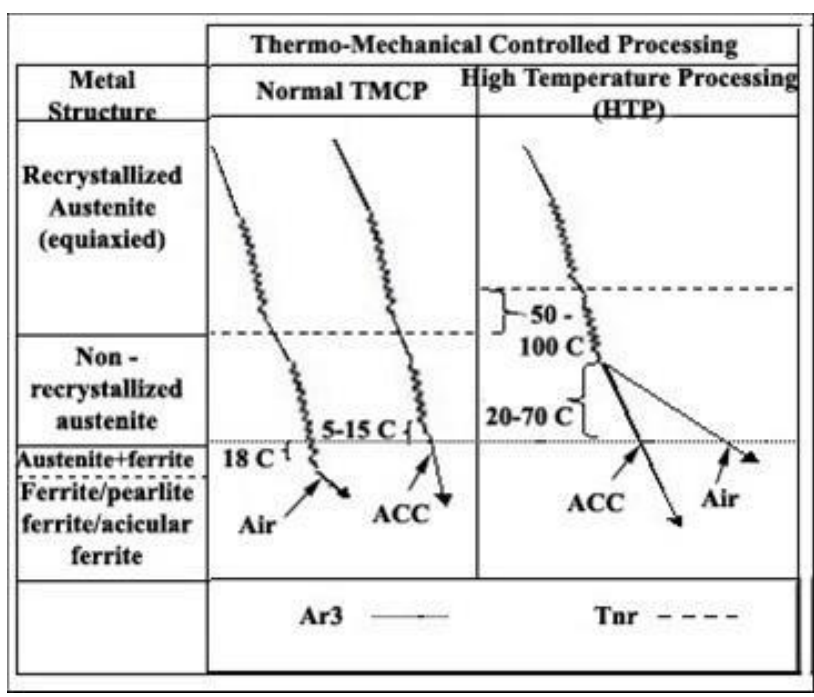

Figura 2: Desenho esquemático da diferença básica entre os processos de TMCP e HTP [3].

\section{MODELAMENTO MATEMÁTICO NA LAMINAÇÃO DE TIRAS A QUENTE STECKEL}

O sistema de controle da linha de laminação apresenta funções tecnológicas que são totalmente integradas através do sistema de automação [4,7]. Isto inclui o planejamento e controle de produção, modelos matemáticos e controle do processo e os equipamentos elétricos básicos (medidores on-line e motores).

A Tabela 1 descreve as etapas dos cálculos que são realizados nos modelos matemáticos da linha e a Figura 3 mostra o fluxograma esquemático da sequência dos cálculos. É importante ressaltar que os cálculos são atualizados em função do intervalo de tempo e corrigidos no momento que são efetuadas medições (força e torque de laminação, espessura e temperatura da tira).

Tabela 1: Cálculos realizados pelo modelo matemático do laminador.

\begin{tabular}{|c|l|}
\hline Etapas & \multicolumn{1}{c|}{ Descrição } \\
\hline $\begin{array}{c}\text { precalc } \\
\text { (setup do } \\
\text { laminador) }\end{array}$ & $\begin{array}{l}\text { O objetivo do "precalc" é determinar a escala de passes completa. Ele inicia } \\
\text { na frente do descarepador utilizando a temperatura de desenfornamento. } \\
\text { Este cálculo é realizado novamente utilizando a temperatura real da placa na } \\
\text { entrada do laminador. }\end{array}$ \\
\hline postcalc & $\begin{array}{l}\text { O objetivo do "postcalc" é adaptar os coeficientes do modelo às condições } \\
\text { reais (força de laminação, torque, gap, força de bending, etc.) para o passe } \\
\text { sucessivo. Essa adaptação é realizada após cada passe comparando os } \\
\text { resultados reais versus os resultados calculados. }\end{array}$ \\
\hline recalc & $\begin{array}{l}\text { O objetivo do "recalc" é executar um novo cálculo dos passes restantes, } \\
\text { baseado nos resultados obtidos no 'postcalc'. O 'recalc' considera nos } \\
\text { cálculos a correção de temperatura em função de atrasos no processo e/ ou } \\
\text { mudanças no 'input' realizadas pelo operador. }\end{array}$ \\
\hline adapt & $\begin{array}{l}\text { O objetivo do "adapt" é adaptar todos os modelos para a próxima placa. Essa } \\
\text { adaptação não é realizada passe a passe, mas sim placa a placa. }\end{array}$ \\
\hline
\end{tabular}

* Contribuição técnica ao $51^{\circ}$ Seminário de Laminação - Processos e Produtos Laminados e Revestidos, 28 a 31 de outubro de 2014, Foz do Iguaçu, PR, Brasil. 

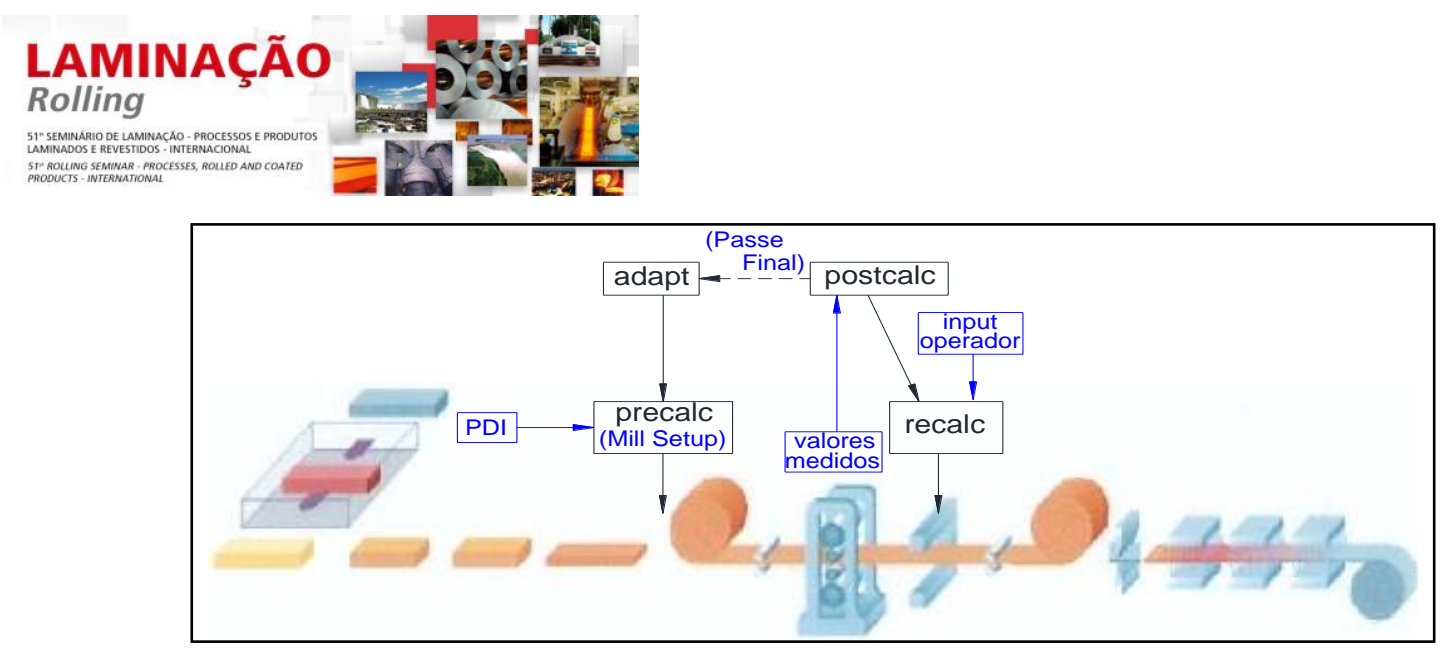

Figura 3: Fluxograma esquemático da sequência dos cálculos realizados no laminador.

O modelo de esquema de passes determina a máxima redução possível em cada passe seguindo as limitações do laminador (ângulo máximo de mordida, redução máxima por passe, valor máximo da força de laminação e torque) e as restrições de processo (temperatura de laminação, dimensional e planicidade da tira). Esse cálculo se repete até atingir a espessura de acabamento, e assim se obtém todos os passes desde a espessura da placa até a espessura final da tira.

O modelo de esquema de passes interage com os demais modelos da linha de laminação (força, torque, bending, temperatura, velocidade) fornecendo os seguintes valores de referência para cada passe: posição da abertura de cilindros (GAP), velocidades de laminação, força de laminação e bending, posição do shifting, torque, dimensões nominais da tira, quantidade de água de refrigeração dos cilindros de trabalho, e ganhos dos controles dinâmicos de espessura e perfil (AGC - Automatic Gauge Control, DPC - Dynamic Profile Control).

O esquema de passes completo é gerado automaticamente antes de iniciar a laminação. Durante a laminação o esquema de passes é atualizado a cada passe executado baseado nas dimensões e temperatura do material, assegurando que o produto final esteja de acordo com a especificação.

O modelo calcula múltiplos setups para compensar a variação de resistência do laminado em função da variação de temperatura ao longo do comprimento da tira, obtendo assim espessuras mais homogêneas entre as extremidades e o corpo da tira. Como a temperatura nas pontas decresce fortemente em função da redução de velocidade para finalizar ou iniciar o passe na fase de acabamento, a força de laminação e espessura da tira tem a tendência de serem maiores nas pontas. A função taper minimiza essas diferenças de espessura nas pontas e, como consequência, ocorre uma leve redução da força de laminação nas pontas dos próximos passes.

O sistema de controle do perfil e planicidade (PFC - Profile and Flatness Control) da tira laminada a quente visa garantir os limites especificados de coroamento e planicidade da tira. O controle do PFC é executado através dos seguintes atuadores: Sistema de WRB (Work Roll Bending), sistema de WRS (Work Roll Shifting), Smart crown, sistema de ajuste de coroamento térmico dos cilindros e distribuição de carga nos passes de laminação (esquema de passes). O controle de nível 2 executa os cálculos dos set points e envia para o grupo de atuadores (setup e ganhos) para 0 sistema de controle do nível 1.

A Figura 4 mostra uma medição da força de laminação através da célula de carga e uma medição da força de bending através do transdutor de pressão. Uma variação da força de laminação e/ou da força de bending $(\Delta F-F b)$ gera uma variação no perfil da tira. Caso ocorra essa variação o sistema será corrigido através do controle dinâmico (DPC). 

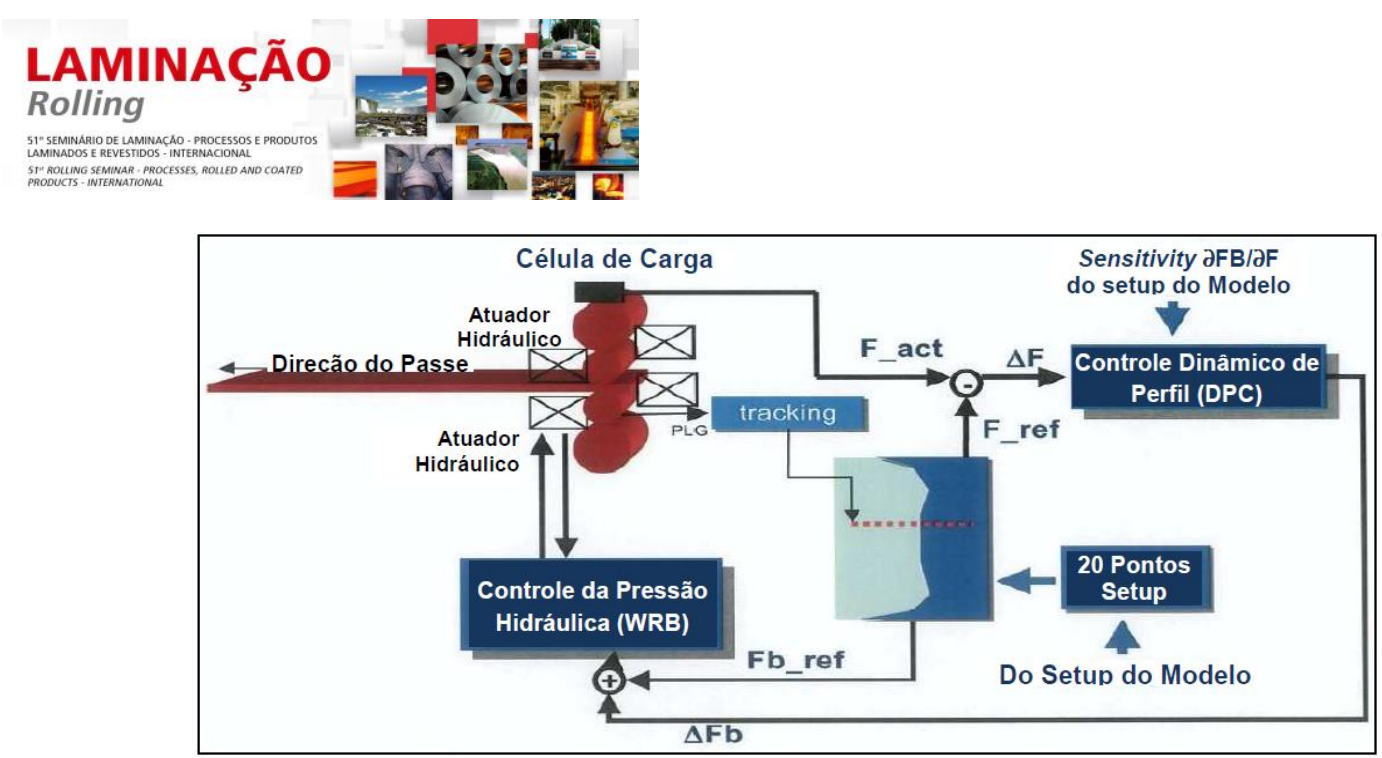

Figura 4. Desenho esquemático do funcionamento do Bending.

O Smart crown [6] consiste na utilização de cilindros especiais que possuem perfil em formato senoidal. O controle de perfil de GAP se dá pelo deslocamento dos cilindros em direções axiais (coroamento positivo, negativo ou neutro).

A carga de laminação certamente é o parâmetro quantitativo mais importante deste processo de conformação. A carga afeta os seguintes parâmetros: solicitações mecânicas das cadeiras e seus componentes, potência e torque dos motores de acionamento, precisão dimensional e planicidade da tira. A Figura 5 mostra os dados que alimentam o modelo de Força e Torque e os modelos que dependem desse resultado. Esse modelo é alimentado por um modelo de tensão de escoamento que é ajustado através de uma rede neural e leva em consideração a composição química, a temperatura, a deformação e a taxa de deformação do material.

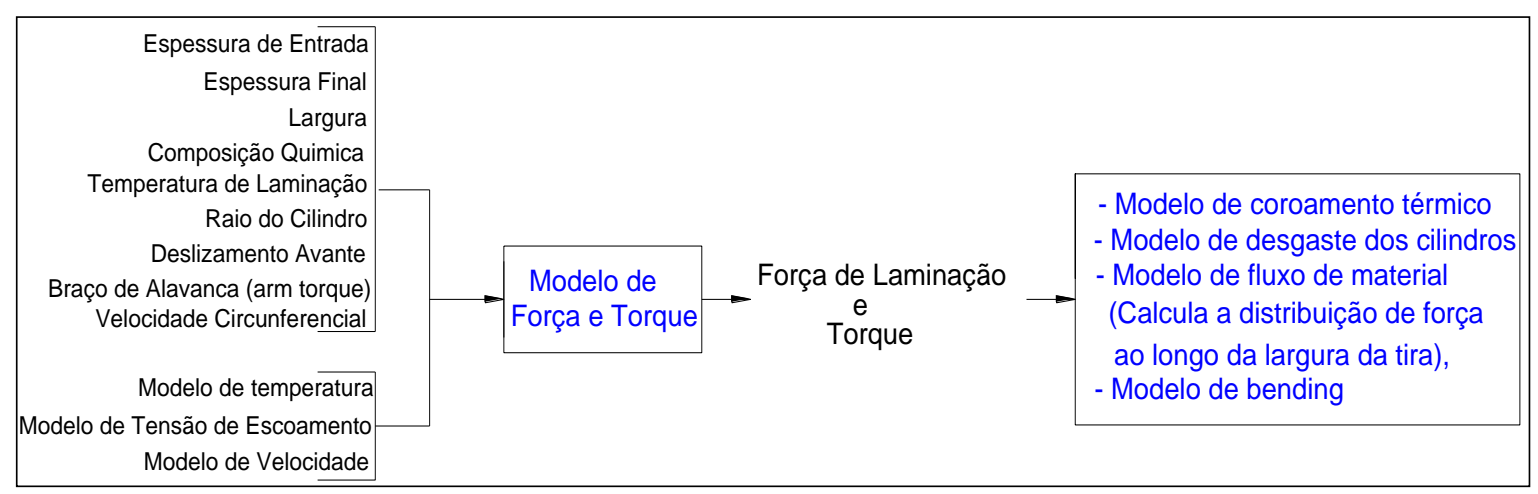

Figura 5: Dados que alimentam o modelo de Força e Torque e os modelos que dependem desse resultado.

O sistema laminar é o elemento final de controle para ajuste das propriedades do aço. O controle da taxa de resfriamento da tira é fundamental para garantir as características microestruturais e propriedades mecânicas do produto através do resfriamento controlado e da temperatura de bobinamento.

O modelo de resfriamento do sistema laminar é resultado da interação de três submodelos: modelo de temperatura, modelo de transferência de calor e modelo de transformação de fases [5]. O modelo é capaz de realizar os cálculos em tempo real considerando rapidamente as interações dos diferentes efeitos, tais como flutuações na velocidade, temperatura final de laminação, vazão e temperatura da água.

Todos os mecanismos de transferência de calor são modelados com bastante precisão e estão ilustrados na Figura 6.

O modelo de Transformação de Fases é considerado o centro do modelo de

* Contribuição técnica ao $51^{\circ}$ Seminário de Laminação - Processos e Produtos Laminados e Revestidos, 28 a 31 de outubro de 2014, Foz do Iguaçu, PR, Brasil. 


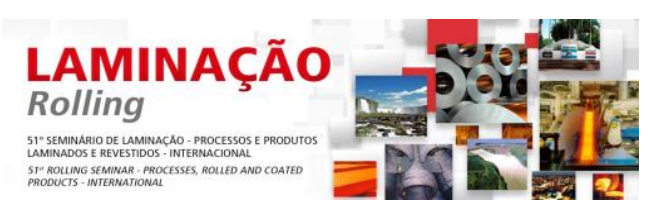

resfriamento e é responsável pelo cálculo das frações de cada fase (ferrita, austenita, perlita e cementita).

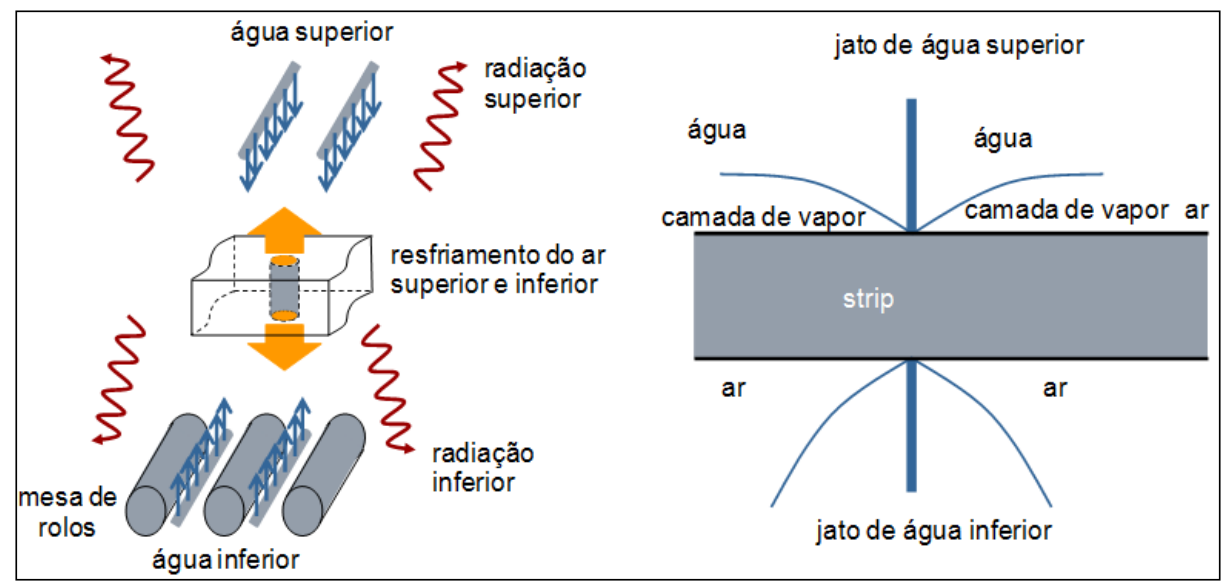

Figura 6: Exemplo de fatores que influenciam na perda de calor.

\section{FUNDAMENTOS METALÚRGICOS DO PROCESSO HTP}

Os aços laminados pelo processo HTP são uma alternativa adequada para aplicações de aços com boa resistência, boa tenacidade, boa ductilidade e boa soldabilidade quando produzidos em laminadores de tiras a quente.

Esses aços têm também grande versatilidade e flexibilidade quando produzidos em laminadores de chapas grossas que utilizam resfriamento acelerado em sua linha, uma vez que existe a possibilidade de definir uma maior faixa de trabalho dos parâmetros de processo: tempos de processamentos, taxas de deformação, temperatura e taxa de resfriamento $[8,10]$.

Esses aços tem composição característica com teores aproximados de carbono de $0,02 \%$ a $0,04 \%$, nióbio $0,08 \%$ a $0,1 \%$ e manganês de 1,5 a $1,75 \%$. O papel desse nióbio mais elevado em relação a tipos de aço laminados com outros processos é retardar e até suprimir a recristalização em baixas temperaturas. Com isso, a microestrutura final obtida é muito mais refinada com precipitados de carbonitretos mais dispersos e finos, em função do maior teor de nióbio em solução no aço. Aços com essa composição típica podem ser produzidos em condições mais amenas de carga, temperatura e resfriamento durante a laminação.

A postergação da transformação ferrítica gera uma maior fração de bainita, uma maior proporção de precipitados de nióbio, um menor tamanho de grão e consequentemente aumento na resistência mecânica sem prejudicar a tenacidade e a ductilidade. Esse conceito de liga também permite produzir aços resistentes a trinca de hidrogênio para aplicações sour services (HIC), basicamente em função da tendência de redução dos níveis de segregação devido ao menor teor de carbono contido no aço.

A Figura 7 representa um diagrama CCT típico de um aço HTP após deformação, onde é mostrado que em menores taxas de resfriamento já se consegue uma estrutura bainítica acicular [8]. 


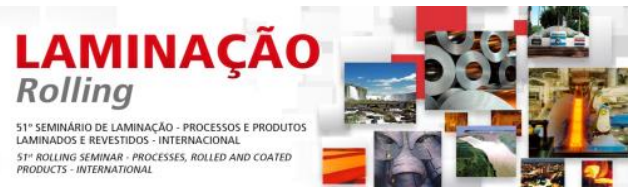

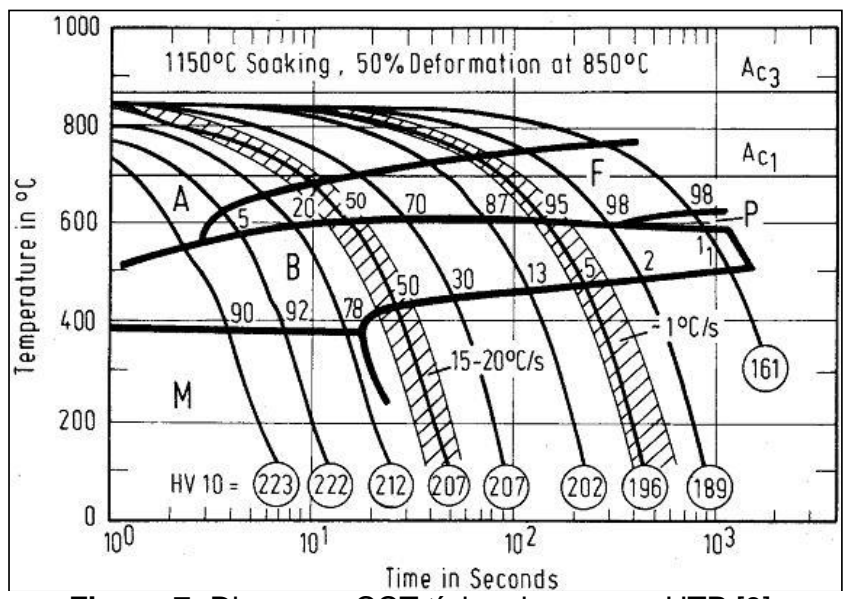

Figura 7: Diagrama CCT típico de um aço HTP [8].

A Figura 8a mostra a influencia do nióbio em solução sólida relacionada ao processo de laminação na formação da fração volumétrica de bainita em aços HTP.

As propriedades de soldabilidade dos aços HTP são comparáveis com aços obtidos em outros processos de laminação. A tenacidade na zona afetada termicamente pela solda nos aços HTP é boa e a Figura 8b mostra uma comparação entre as energias de impacto obtidas de aços HTP (API X80) versus aços não HTP (API $\mathrm{X} 70$ ). Esta menor tenacidade é devido a microestruturas bainíticas de baixo carbono obtidas em diversas condições de resfriamento (Figura 7).

Sabe-se que a resistência final do tubo é função da microestrutura do aço laminado e do tipo de processo utilizado na fabricação do tubo: UOE ou helicoidal, por exemplo. Para o aço HTP, deve-se levar em conta que a resistência mecânica deste aço como bobina a quente é a mesma resistência do tubo quando ele é produzido através do processo helicoidal. Assim deve-se levar em consideração durante a laminação os parâmetros de temperatura, redução e taxa de resfriamento para a correta definição do projeto de produto. Uma vez que esses parâmetros vão estabelecer a microestrutura final do laminado: perlítica ou bainítica acicular.

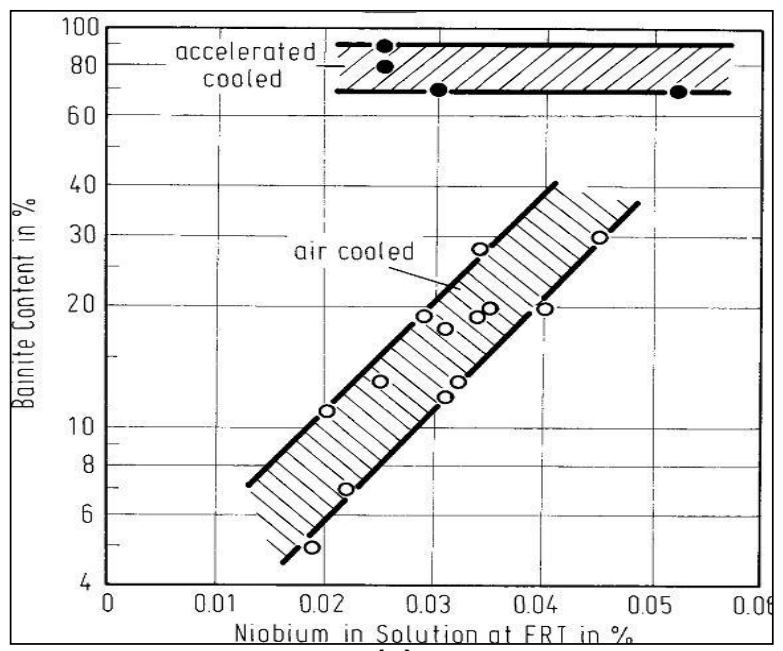

(a)

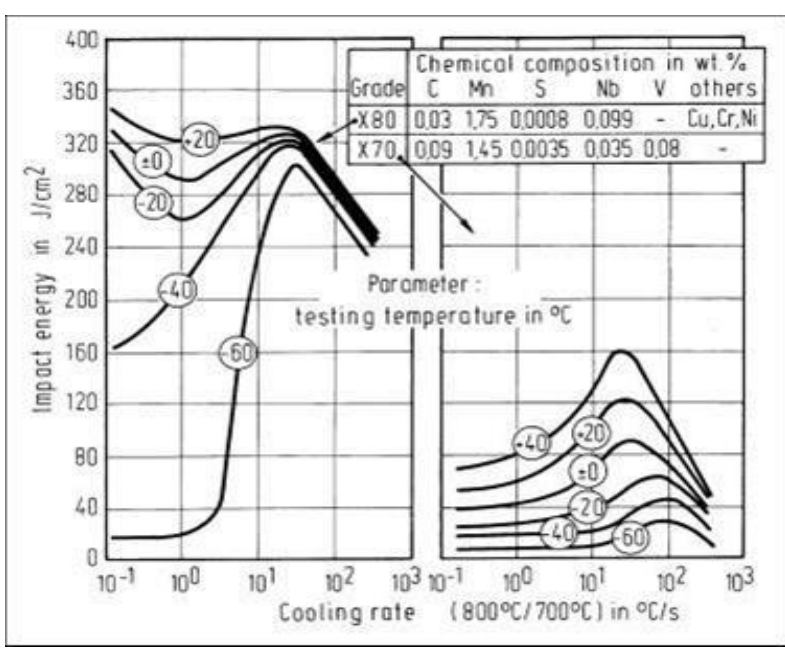

(b)

Figura 8: (a) influencia do nióbio em solução sólida relacionada ao processo de laminação na formação da fração volumétrica de bainita em aços HTP e (b) comparação entre as energias de impacto obtidas de aços HTP (API X80) versus aços não HTP (API X70) [8]. 


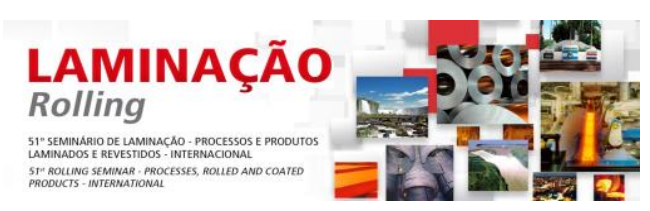

A atual tendência mundial de utilização de aços resistentes a HIC, SSC utilizados em ambientes marinhos agressivos (sour service) tem levado ao desenvolvimento de novos aços isentos de segregação, alto nível de limpidez interna e com baixíssimos teores de S, O, N e H. Conforme Malcolm Gray ${ }^{(9)}$, menor nível de segregação é alcançado quando o $\mathrm{Mn}$ é menor que $0,30 \%$ e carbono menor que $0,05 \%$. $\mathrm{O}$ processo HTP é ideal para produzir esse tipo de aço laminado.

\section{CONCLUSÃO}

O laminador de tiras a quente da Gerdau apresenta alto grau de automação com integração completa dos modelos matemáticos de processo que promovem melhoria de forma, dimensão, rendimento e qualidade das tiras laminadas. Com o domínio do processo, o desenvolvimento de aços de alta resistência e alta tenacidade do tipo HTP (High Temperature Processing) é amplamente atendido, seguindo as normas técnicas e às exigências de mercado.

\section{REFERÊNCIAS}

1 Stalheim DG, Yin Y, Yao Y, Gray JM, Siciliano F. Development and Capability of High Temperature Processing (HTP) Pipeline Steel at Nanjing Iron and Steel Company. $9^{\text {th }}$ International Pipeline Conference 2012, Calgary, Canada.

2 Collins LE, Hamad F, Kostic M, Lawrence T. Production of High Strength Linepipe Steel by Steckel Mill Rolling and Spiral Pipe Forming. IPSCO, Frontier Pipe Research Unit.

3 Stalheim DG. The Evolution, Review and Optimization Next Steps Related to the High Temperature Processing (HTP) Alloy Design for Pipeline Steel in China. International Pipeline Technology Conference, pp. 2, 2010

4 Pichler R, Brammer M, Farnik A. VAI Plate Mill Automation - The Leading Plate Mill Quality Improvement Package. Metal 2003, mai. 2003.

5 Weinzierl K, Loffler H. Unified Temperature Control. Metals \& Mining, pp. 76-79, 2011.

6 Wilms W, Stahl T. Profile and Flatness Control in Hot Strip Mills. Metallurgical Plant and Technology, pp. 74-90, jun.1985.

7 Siemens VAl. Siroll Solution for Hot Strip Mills. Metals Technologies, pp. 13-31, 2009.

8 Hulka K, Gray JM. High Temperature Processing of Line-Pipes Steels. Microalloyed Steel Institute.

9 Gray MJ. Low Manganese Sour Service Linepipe Steel. Microalloyed Steel Institute.

10 Yong- Dong L, Ming L, Yong-Qing Z, Wei J, Jian-Hui L, Fei L. Application HTP Process to Produce X80 Strip for $2^{\text {nd }}$ West- East Gas Pipeline Project. The $6^{\text {th }}$ International Conference on High Strength Low Alloy Steels (HSLA Steels 2011). 